\title{
Learning as Lack: Individual Learning in Organizations as an Empowering Encounter with Failed Imaginary Constructions of the Self
}

\author{
By Michaela Driver, Ph.D. \\ Department of Business, Accounting \& Economics \\ Western State College of Colorado \\ 221 Borick Business Building \\ Gunnison, Colorado \\ USA \\ Tel: $970-943-2673$ \\ Fax: 970-943-7042 \\ E-mail: mdriver@western.edu
}

\section{Biographical Note:}

Michaela Driver is Professor of Business Administration at Western State College of Colorado where she teaches Organizational Behavior and Human Resource Management. Michaela researches alternative and psychoanalytic approaches to a wide range of organizational topics such as organizational identity and learning, emotions, organizational interventions, spirituality, corporate social responsibility, identity work, creativity, embodied subjectivity and journal reviewing. Journals in which Michaela's work is published include Human Relations, Organization Studies, Organization, Management Learning, Journal of Organizational Change Management, Tamara, Journal of Business Ethics, and Journal of Management Inquiry. She serves on several editorial boards including Management Learning, and the Journal of Management Inquiry. 


\title{
Learning as Lack: Individual Learning in Organizations as an Empowering Encounter with Failed Imaginary Constructions of the Self
}

\begin{abstract}
The purpose of this paper is to draw on psychoanalytic, particularly Lacanian, theorizing, to examine individual learning as an empowering encounter with fundamental lack. Specifically, I explore learning as an imaginary construction of the learner's self that invariably fails thereby providing opportunities for the experience of empowerment and liberation. I discuss the implications this has for how we conceptualize and experience learning as an emancipatory discourse in organizations.
\end{abstract}

Key Words: Individual Learning, Psychoanalysis, Lacan, Discourse 


\section{Introduction}

Prior research has found that learning in organizations changes not only what we do and how we see things around us (Hardless, Nilsson and Nulden, 2005) but also who we are (Fletcher and Watson, 2007). Specifically, it has been found that learning changes

our identity (Cunliffe, 2002; Fenwick, 2005; Parker, 2004) by changing our discourse and how we narratively construct our selves (Cortese, 2005; Cunliffe, 2002; Hemetsberger and Reinhardt, 2006; Hughes, 2000). Moreover, because learning changes our narratives, it also invites critical reflection and serves as an emancipatory space in which we may contest power and control in organizations (Bryans and Mavin, 2003; Cunliffe, 2002; Fenwick, 2005; Ferdinand, 2004; Fletcher and Watson, 2007; Hughes, 2000; Lorbiecki, 2001; Reynolds, 1998; Vince, 2002; Vince and Saleem, 2004).

The aim of this paper is to build on these insights and explore learning further with regard to its relation to discourse, identity work, and emancipation by developing a psychoanalytic perspective on individual learning. In particular, I draw on the theories of French psychoanalyst Jacques Lacan who built on Freudian insights to focus more extensively on language and how individuals consciously and unconsciously construct the self in discourse (Lacan, 2001). This perspective was chosen not only because it extends prior psychoanalytic theorizing on learning in organizations (Vince, 2002; Vince and Saleem, 2004). Importantly, it was selected because it provides crucial insights into how identity is constructed in discourse and what this may mean for the emancipation of subjects. As I will explain in more detail later, Lacanian psychoanalysis suggests that our identity, or, more precisely, the self is always constructed in and through discourse but that what we consciously claim to know about who we are and what we want is an 
illusion. This illusion is constantly undermined by our unconscious. Therefore, what may seem real on the surface is, for Lacan, a fantasy designed to cover up a lack that is impossible to get rid of. Indeed, for Lacan, the individual is only ever close to being authentic when failed fantasies of the self are rendered transparent.

As such, what provides us authenticity are experiences of our failed fantasies or when we notice in our narratives through myriad failures of speech, such as contradictions, omissions, tangents and other rhetoric constructions, how we are not who we say we are and may not want what we say we want. What we notice at those moments is that something in us continuously asserts that our illusions can never define or satisfy us and that we, as subjects of the unconscious, are creative, powerful and free. As subjects, we are creative in how we continuously disrupt our conscious self(mis)constructions. We are powerful in that our lack keeps reasserting itself. And we are free in those moments of the egoic illusions that trap us by believing that we know who we are and can fulfill our desires. In short, by noticing how our conscious, imaginary self-constructions are always already lacking and reiterate our lack, we have opportunities to experience that we are authentic in our search for answers that invariably fail and fulfilled only insofar that we assert our desire to desire, or to continue to desire what we fail to attain.

Given these insights on the construction of identity in discourse and the power of individuals as subjects of the unconscious, I propose that Lacanian theorizing provides an important new perspective on individual learning in organizations. Specifically, it suggests that learning is related to identity work as both the construction of a conscious illusion as well as its failure and, therefore, an important opportunity to experience the 
self as powerful and free. As I will show below, a Lacanian perspective may enable us to appreciate learning in organizations in a radically different and to date under-explored fashion, namely as conversations that render transparent learning as a failed fantasy of the self and therefore celebrate and potentially enhance learner's power, creativity and freedom.

As I will illustrate with empirical data drawn from prior research (e.g. Rigano and Edwards, 1998), the, as one reviewer for this manuscript described it, "positive value" of exploring individual learning in organizations from a Lacanian perspective is to uncover that learning may be empowering in ways we have not considered before. Specifically, it allows us to see that what we might think is empowering from a conscious perspective is not nearly as liberating as we thought. Conversely, learning may be quite empowering from an unconscious perspective.

In particular, a Lacanian perspective reveals that it may be equally illusory to claim that we have learned $\mathrm{X}$ as saying that we have failed to do so. Conversely, it may be significantly empowering to understand that this is the case and in doing so to assert that, as subjects of the unconscious, we can never learn what we wish to learn and thus never stop wishing to learn. Put simply, the perspective developed here suggests that because we cannot learn who we are and what we want, we can experience power, creativity and freedom from our insatiable desire to do just that.

The paper proceeds as follows. I first review key Lacanian ideas on the construction of the self in discourse. Then I apply these ideas to develop an alternative perspective on individual learning in which learning is both an imaginary construction 
and an encounter with its failure. I conclude by discussing the implications of this perspective for the study of individual learning in organizations.

\section{Lacanian insights on the construction of the self}

This section contains a brief expose of relevant psychoanalytic concepts. In this expose I draw on Lacan's original writings (Lacan, 1977a;b;1988a;b; 2001) and recent applications of his thought to organization studies where further introductions can also be found (Arnaud, 2002; 2003a;b; Arnaud and Vanheule, 2007; Driver, 2005; 2006; 2008; 2009a;b; Fotaki, 2009; Harding, 2007; Jones and Spicer, 2005; Roberts, 2005; Vanheule, Lievrouw and Verhaeghe, 2003).

Lacanian conceptions of subjectivity draw our attention to everyday speech and how, in conversations and discourse with others, we construct the self. Nearly everything we say consciously is designed to present the self as a definable, knowable and stable object. This self knows who it is and what it wants and can obtain what it wants to fulfill its desires. From a Lacanian perspective, however, this self is an imaginary construction, an illusion or fantasy of the ego.

It is a fantasy because the self we construct in the imaginary order is always constrained by language and, what Lacan described as, the symbolic order. As we try to articulate in an authentic fashion who we are and what we want, we are always using language, which consists of words, structures and conventions made by others, even generations of others. Therefore, the language through which we construct the self is not authentic in the sense that it does not reflect who we really are or what we really desire.

Who we really are and what we really desire is to return to a primal womb-like state of feeling whole and complete. But given that we can only construct the self in a 
symbolic order, this primal state or, what Lacan referred to as, the order of the real, is lost to us. All that remains of it is our longing for it and our continuous articulation that we are missing something and experiencing fundamental lack.

Lacanian psychoanalysis offers no cure for this condition. Indeed, it suggests that we can neither leave behind illusory imaginary constructions, nor overcome our fundamental lack. However, what it does suggest is that we can recognize how our imaginary constructions invariably fail as we express ourselves in a language that is not of our own making and does not tell us who we are or allow us to fulfill our desires. Recognizing this requires paying attention to and reflecting on the numerous distortions, contradictions, tangents, omissions, unusual constructions, ambiguities and other failures points of speech that mark our daily, conscious and common narratives.

Lacan suggests that recognizing these failure points as imaginary constructions of the self does not mean that we can explain and correct them because doing so would only lead to more illusion. Rather what we can do is simply to notice them as instances when we return to being authentic subjects of the unconscious. We are authentic because at those moments we are connected to our initial womb-like state by how we relive its loss. Every individual does so in unique and creative ways. So when we amplify and hold up for reflection how we fail in our imaginary constructions we get a momentary experience of empowerment and liberation when we realize that all we pursue consciously is never enough. It can never contain our true desires or who we truly are. As subjects of the unconscious we will always disrupt conscious constructions as we circle around what marks us, namely the primal experience we have lost. 
To summarize, three insights emerge from Lacanian theorizing that seem to be relevant for learning in organizations. One, conscious speech consists of imaginary constructions of the self. Two, these constructions continuously fail as they are disrupted by unconscious desires. Three, recognition of and reflection on this failure provides opportunities to experience the self as a creative, powerful subject of the unconscious that is free of and can never be contained by an imaginary order.

\section{Individual Learning as an Imaginary Construction of the Self}

In this section I apply Lacanian insights on the imaginary construction of the self to how individuals construct the self in and through learning in organizations. Learning in organizations has been described as both a linguistic and identity-based phenomenon (Gherardi, Nicolini and Odella, 1998). Recent research has focused on language and discourse as a prefabricated line of argumentation (Sveningsson and Alvesson, 2003) not only to explore the socially constructed nature of learning (Hemetsberger and Reinhardt, 2006), but also to examine how individual identity is enacted and changed in and through learning (Baker, Jensen and Kolb, 2005; Cunliffe, 2002). Moreover in what might be called a "subjective turn" (Perriton, 2007: 155) in the field, there is also a focus on learning as a process of opening up the individual, rendering the self more transparent and vulnerable and seeking to tailor experiences more to the narcissistic needs of learners and facilitators (Perriton, 2007). In general, conceptualizations of individual learning seem to focus on learning as the changing of self and other (Baker et al., 2005), the transformation of identity (Cunliffe, 2002) and the expectation that learning produces and is produced by personal development (Van der Sluis and Poell, 2002) and fulfills 
“participants' wishes” (Hardless et al., 2005: 193) for enhanced self-knowledge and transformation (Perriton, 2007).

Participants of learning activities are said to be able to assess that they have learned (Hardless et al., 2005). Learners are said to become capable of changing their inner reality, uncovering core qualities of the self and altering the boundaries of their ego (Korthagen, 2005). The self of the learner is said to be not only invested heavily in the learning process but is also described as an object that can be known and changed by it (Cope, 2003). Learning seems to be connected to knowing or discovering the self (Bryans and Mavin, 2003), transforming the self's inner core and reality (Korthagen, 2005) and fulfilling its desires (Hardless et al., 2005). In short, in learning the self is conceived of as having a definable and malleable identity (Perriton, 2007) and as being capable of articulating and fulfilling its wishes whether these are to learn in general or to learn about and change the self in particular.

The Lacanian perspective developed earlier suggests that such conceptions of learning are likely part of imaginary constructions of the self. Specifically, narratives that are said to articulate learning processes seem congruent with imaginary constructions of the self as an object of the ego. If learning entails a discourse of self-discovery and transformation as well as fulfillment of desires, then, from a Lacanian perspective, it also entails the construction of imaginary selves. When learners talk about their learning experiences and how learning changes who they are and what they want, then they are, from a Lacanian perspective, talking about an illusion in which they can have or develop authentic knowledge of who they are and fulfill what they want. 
This does not mean that learning as it is conceptualized is somehow wrong or badly practiced or that we cannot consciously articulate a genuine desire to learn. Rather it means that learning as it is articulated by individuals is likely part and parcel of their normally conscious but illusory self-construction and therefore authentic and empowering in ways that are unexpected and easily overlooked. Consequently, a Lacanian perspective highlights that when we focus on learning as a linguistic and identity-based phenomenon (Gherardi et al., 1998) with emancipatory potential (Cunliffe, 2002), there are important, specifically unconscious, dynamics, of learning as imaginary constructions of learners' selves that may be worth exploring.

I would like to illustrate this further by examining prior research in which the narratives of learners and learning as identity change were studied in detail. Specifically, I would like to provide excerpts from prior qualitative research on learning in organizations. These excerpts were selected in a reflexive and iterative process (Alvesson and Skoldberg, 2000). I first reviewed the literature on individual learning in organizations going back about 20 years. I selected all empirical research and then narrowed it down to studies using qualitative methods. Finally, I selected studies with narrative data such as personal accounts, stories, interviews or journal entries relating to the learners' experiences. This resulted in a set of six studies quoted below in which I examined learners' narratives from a Lacanian perspective.

These secondary data and my subsequent interpretations of them are presented here not as valid proof but as one interesting argument in a continuing debate (Alvesson and Skoldberg, 2000: 276). As such, it is worth underlining that the perspective I advance here is performed by many and sometimes contradictory voices including the readers of 
this manuscript who alter its meaning over time (Boje et al., 1999). Therefore, while the narratives I selected may be read from a Lacanian perspective, it is important to acknowledge that they may also be read from other perspectives, such as how learning is not so much a failed fantasy as it is constrained by, as one reviewer for this manuscript put it, "organizational culture, results-driven expectations, power and gender discourses". Here, in order to illustrate a Lacanian perspective on learning, I emphasize how learning may be understood in the context of imaginary constructions of the self.

The first excerpt I examine in this context is drawn from a study of a development program designed to introduce reflection into work practices during which participants were asked to keep learning journals in which they recorded reflections on their learning experiences. The following narrative was written by a participant named Vincent:

I think I need to learn to use it [book recording daily reflections]...just by the nature of me, I'm very reluctant to talk about thoughts or whatever else and it's just not natural for me to put thoughts down on paper...It turned out that a lot of the problems were in my own sphere... This confirms my impression of my world view in this context and highlights that the world view must change...I notice that I automatically started to use the small range of lateral thinking techniques that I found interesting...these techniques definitely helped as the bank of normal personal ideas ran out. I must spend time reviewing, reflecting on, and practicing these techniques, as they appear to work...I am attempting to listen for what people are saying. This takes conscious effort and is not easy. I notice that reflecting on actions, moment of freedom, and consideration of perception flows over into non-work activities as well (Rigano and Edwards, 1998: 437-440).

In this narrative, Vincent shares insights about what he is learning about himself. He describes himself in terms of his "nature" and what is "natural" to him. The self is constructed as a definable object with its own "sphere". Importantly it is constructed as having definable desires such as to make changes in its "world view", "ideas" and "practices". The narrator points to the possibility of fulfilling his desires as he resolves to 
reflect and listen more and how doing so affects other areas of his life. In short, learning discourse is drawn on to construct an imaginary self which can be known and defined and whose wishes can be fulfilled.

Consequently, as we explore descriptions of how learning changes identities and conversations, it is important not to miss how individuals also use learning discourse to construct imaginary selves. In other words, I am suggesting that we pursue the "subjective turn" (Perriton, 2007:155) in research on individual learning in organizations further to explore its imaginary qualities. Therefore, when learners discuss who they are, what they have learned, wish to learn or change, this can always also be examined as a way to validate the egoic order and as further trapping the self of the learner in this order.

The feedback of participants in a leadership program (Blackler and Kennedy, 2004) may illustrate this point further. One participant writes: "The programme has helped me to step back and rebalance. I have valued the chance to look at issues in different ways..." (Blackler and Kennedy, 2004: 189). Another comments:

The mutual reinforcement and peer support reminded me that although local issues can seem particularly difficult, many others are grappling with similar issues. As to longer term benefits, I expect these to emerge as I go away and absorb the learning. I think of it as a work in progress (Blackler and Kennedy, 2004: 189).

What emerges in both these comments is that the narrators construct a self that can do things like step back, rebalance and look at things differently and therefore can know itself and most importantly fulfill its desire, especially the desire to know itself more and to pursue its own development and improvement.

In this sense the self, through learning, can not only increase self-knowledge and wish-fulfillment through transformation and new insights, such as different perspectives 
or an understanding of what others are dealing with but also through narrating the self as a "work in progress" (Blackler and Kennedy, 2004: 189). That is, learning discourse becomes a means for narrating not only how we can know the self but also how we can fulfill its wishes by continuously working on it and progressing along a trajectory of improvement. This gives the hope that even if desires cannot be fulfilled in the present, they can be fulfilled in the future. Therefore, learning discourse becomes part of or is sucked into imaginary self-constructions where the learner can know the self and fulfill desires. Such imaginary self-constructions are, from a Lacanian perspective, neither authentic nor transformative as they only trap the self further in egoic illusion and an imaginary order by which we seek to constrain the self as an object of the ego.

What is important here is not to view this as a critique of how learning is wrongly conceived of as a process of knowing or changing the self but to highlight this as an imaginary construction that is part and parcel of how we all consciously and commonly construct the self in discourse. In other words, since, from a Lacanian perspective, we always construct the conscious self in an illusory fashion, it would be surprising to find that narratives describing learning would not also do this. As such, from a Lacanian perspective, the "subjective turn" (Perriton, 2007: 155) in the learning field not only highlights common and "normal" dynamics of self construction, it also reveals a dynamic that is worth paying more attention to, namely how learning may become an opportunity for rendering transparent the failure of the imaginary, which I discuss below.

\section{Individual Learning as a Failed Imaginary Construction of the Self}

It has been suggested that individual learning in organizations is prone to failure because the changes that are expected to occur as a result of learning often do not happen 
or do not improve organizational performance (Hardless et al., 2005). As a result learning interventions are often accompanied by disappointment and cynicism (Hardless et al., 2005: 210). Others have suggested that learning often fails because even, or especially, if results are delivered, learning is highly constrained by managerial ideologies and the imperative that learning support existing, tightly controlled and imposed goals but cannot be used to question those goals or to learn something other than what is considered performative (Contu, Grey and Oertenblad, 2003: 936).

What I would like to examine here is how such failures may be explored as failed imaginary constructions of the self for particular individuals. Specifically, I would like to explore how learning fails not because it fails to deliver results or to question the performative (Contu et al., 2003) but because it fails to articulate who we say we are and to achieve what we say we want. In other words, I would like to explore learning as a particular expression of failed imaginary constructions of the self but also as important opportunities to reiterate lack and assert the power, creativity and freedom of the self as subject of the unconscious. So for example, we can examine the concerns of learners as failed imaginary self-constructions:

We attend seminars and lectures about all kinds of project issues, but our projects are not becoming any different (Hardless et al., 2005: 210).

And while this may on one level underline the failure of learning in terms of performative goals, from a Lacanian perspective it points to the inevitable failure of all conscious imaginary constructions by which we can say with certainty who we are and what we want by, for example, explaining how we would like to change or become different. What I am suggesting is that the excerpt above points to an important encounter with how 
we can never be satisfied with our projects or anything we become through work or organizations (Arnaud and Vanheule, 2007) because what we are really searching for is always missing.

Therefore, when individual learners encounter a lack of learning or the absence of learning, as this learner seems to have when describing barriers to learning in the organization:

We do not have a learning culture. There are too many blocks in terms of personal power building and cultural castles where attitude is you tell me everything I want but I am only going to release what I want you to know (Thursfield, 2008: 303).

They are not only encountering political and emotional barriers to learning in organizations (Vince, 2002), they are also, importantly encountering the impossibility of learning to cover up the lack of self, work and organization (Arnaud and Vanheule, 2007) as a process that brings them closer to an authentic self or authentic wish fulfillment. So it is not just a lack of learning cultures or collaboration that is articulated here but the inability of the learner him/herself to experience learning as an authentic articulation of who he/she is and what he/she wants.

This becomes clear especially when we hold up for reflection what people hope to accomplish through learning processes and what they may or may not have learned. From a Lacanian perspective, learning does not and cannot bring them closer to becoming authentic or even to change in the desired fashion because what is desired is never what is really desired, as subject of the unconscious, namely to overcome fundamental lack. Vincent, the person whose book of reflections I quoted earlier points to the failure of the imaginary most poignantly: 
Am I really doing anything different to what I was doing previously?...I don't really have an answer, but I probably need an answer at this stage to keep moving along the track. It has probably reached the stage where the initial learning process has gone through a mad race, and now I have probably flattened off...the next thing I have to do is say where do I go from here and that's probably what I am struggling with (Rigano and Edwards, 1998: 442).

Here Vincent directly encounters the failure to validate an imaginary self as he admits uncertainty about knowing whether he is doing the same or something different as before. While the narrator seemed to be sure in an earlier excerpt about who he was and what his nature is, here he seems uncertain. He admits to not having an answer as to how the learning may have changed him but he also feels that he should have such an answer. The imaginary always has and demands answers about who we are and what we want. Therefore, the "track" that Vincent refers to may be exactly the imaginary construction of the self that keeps us moving along, generating more answers, only to find, repeatedly, that they do not work. The struggle the narrator refers to is a very real struggle with identity and desire and the encounter, specifically facilitated by learning discourse, with our inability to say who we really are and obtain what we want.

Learning discourse provides opportunities for encounters with our failed imaginary self-constructions not only because it may be designed to encourage selfreflection and a "subjective turn" toward learning that is, as one facilitator puts it: "personally being involved in disclosing, [and] making themselves vulnerable" (Perriton, 2007: 162). From a Lacanian perspective, learning also provides such opportunities when it does not have a specific subjective focus and even if learners are convinced that learning has taken place and benefitted them. For example, one participant of a leadership program for senior executives describes the success of the program and how it has helped 
him particularly in view of the barriers to learning he faces outside of this learning activity:

I've always been a strong supporter of targeted programmes for chief executives. The job is uniquely difficult. There is an enormous wealth of government expectation and a huge amount of personal and organizational pressure. It can undermine your ability to see the wood for the trees...There is often not enough time to reflect and plan more strategically. (Blackler and Kennedy, 2004: 189).

Here we see how the narrator describes the benefits of the program as being targeted to his job and circumstances and giving him time to reflect and plan strategically. Yet we also see how this narrative points to lack. The self that has learned and was developed through the program will apparently still have to face unique difficulties and personal and organizational pressures and struggle with a lack of opportunity to see the wood, reflect and think more strategically.

From a Lacanian perspective, even the successful learning program only points to more lack and reiterates that even learning cannot bring us closer to knowing who we are or what we want because, on the "track" described by Vincent earlier (Rigano and Edwards, 1998: 442) there are always more of what the participant in the leadership program referred to as "difficulties", more "expectations" and more "pressure" (Blackler and Kennedy, 2004: 189). Whatever we encounter consciously, it always "undermine[s] your ability" (Blackler and Kennedy, 2004: 189) because it is not who we are or what we want as subjects of the unconscious.

As we have seen from Vincent's reflections earlier, learning narratives are often articulations of learners' successes but also the failure to attain the specific personal changes they are looking for. One participant in a study to examine how women learn to be managers comments that she is not sure whether she has changed her identity as a 
result of her learning or whether she has effected desired change in the way that the game of management is played. She comments: "I started to become part of the signing up. Am I changing the rules or is it a survival technique? I can choose not to do it or I can do the things that men do but not do it in a pub. I do it at work." (Bryans and Mavin, 2003: 125). What we see in this narrative, as in the others, is that learning discourse is sucked into the learner's struggles with identity and desire, here around the learner's uncertainty with regard to how she may or may not have changed.

Specifically, learning discourse is drawn on not just to construct imaginary selves but also to encounter their failures. As learners reflect on who they are or have become they inevitably experience failure points where they articulate uncertainty about who they are and what they want. As the participant in the leadership program refers to the difficulties of his job that await him after, or in spite of, the program and the manager wonders who she is as she learns about gendered managerial norms, we see that learning discourse contains failures to articulate coherently who we are and what we want as definable objects of the ego. As both are expressing lack of the desired self or lack of achieving what is desired, it becomes apparent that fundamental lack is reiterated.

Learning discourse in this sense is appropriated by subjects as an encounter with lack. This is vividly illustrated in Vincent's narrative when he reflects on the use of group meetings during the development program:

Originally, when I started doing this whole process...I couldn't see any reason to go and talk to anybody about it because probably everyone was staggering along blind as much as I was and I'm not going to waste my time talking to someone who from my point of view knows less about it than I do (Rigano and Edwards, 1998: 441)..

Then he reflects on his comments about these meetings: 
I'd be very careful in talking about some of these things that I've written in this book. They're probably not really all that controversial or need to keep them quiet or whatever else but I'd be stepping totally out of character in going to talk [about] those sorts of things to anybody...So I would be extremely selective who I spoke to about those sorts of things (Rigano and Edwards, 1998: 441).

What we see in these excerpts is the failure of Vincent's imaginary self construction as someone who knows his nature, as he described it earlier, and can work to fulfill his desires for improvement and change. Here we see how Vincent articulates himself as both blind and seeing. He first could not see but had a view. Then we see how he did not know much but was sure he knew more than others. We see how his thoughts have to be kept quiet because others would think them out of character although those others know little and he wishes to change his character anyway. In these contradictions and ambiguities we see that the narrator is always thrown back on his own lack, his lack of self-knowledge and lack of wish fulfillment but also that learning discourse is always sucked into and appropriated for this very experience. The lack of learning in this sense becomes learning about lack as an encounter with who we are not and therefore an opportunity to experience the self as momentarily liberated from egoic illusion.

This seems particularly evident in the narrative of a student in a class designed to encourage critical reflection:

...the more glaring and obvious insights and moments in which my mind was "silenced" by the voice of this course that challenged me to seek a personal identity to an entity I call 'myself'. And if I were to summarize in a few words, the most profound effect was an increased awareness of the absence of an absolute truth, and that the sooner we recognize and come to terms with this, there are endless possiblilities to shape and reshape our world, to color it, and recreate it (Cunliffe, 2002: 48). 
While learning for this narrator was a call to find the self, what is encountered is only an absence of truth and lack. This encounter seems to be liberating and empowering for this narrator as she also describes the realization that there are endless possibilities to shape and recreate the world.

It is precisely the opportunity to experience the self through the creative and liberating disruptions of the unconscious that makes failures of the imaginary not only inevitable but in some sense desirable. As we appropriate learning discourse to assert that we fail to know who we are and what we want, we have the important opportunity to recognize not only "absence" [but] "endless possibilities" (Cunliffe, 2002: 48) for asserting that we will never fulfill and therefore end desire. On the contrary, the absence or lack of answers will give us creativity and power to continue to ask questions and search so that we can keep desiring and keep desire and the self, as subject, alive.

Therefore, when learners voice frustration over how they have failed to change, are uncertain about what they wish to learn or can learn, contradict themselves in how they have learned or who they are as learners or as a result of learning, these are all important moments of liberation and, from a Lacanian perspective, of emancipation from any conscious, egoic, imaginary order. These moments may reveal something about failures of learning as, for example, the failure to deliver results (Hardless et al., 2005), but importantly they are moments of failed imaginary self-constructions. Therefore, they are moments appropriated by the self as subject of the unconscious to assert that all our answers about what we learn and about who we are and what we want will always be lacking. 


\section{Conclusion}

The purpose of this study has been to examine individual learning in organizations from a psychoanalytic, specifically Lacanian perspective, as an encounter with fundamental lack. In particular, I explored how individuals draw on learning discourse to construct imaginary selves with definitive answers about who the self is and what it wants. Such imaginary constructions inevitably fail and I examined how learners draw on learning discourse as an opportunity to encounter who they are not and thereby how learning narratives become an experience of the self as a powerful, creative subject of the unconscious.

The framework developed here makes two important contributions to the study of individual learning in organizations. First, it highlights the importance of examining learning as a linguistic and identity-based phenomenon (Gherardi, Nicolini and Odella, 1998). Specifically, it suggests building on research examining how learning is constructed in discourse (Cortese, 2005; Cunliffe, 2002; Hemetsberger and Reinhardt, 2006; Hughes, 2000) and how it affects learners' identities (Cunliffe, 2002; Fenwick, 2005; Parker, 2004) by exploring how learner selves are constructed in and through learning discourse in imaginary ways. In particular, this study suggests that important underlying dynamics of learning may be uncovered by carefully investigating how particular individuals draw on learning discourse to construct imaginary selves and how these particular constructions invariably fail.

As such, the study invites us to pursue both the "linguistic turn" (Cunliffe, 2002: 37) and the "subjective turn" (Perriton, 2007: 155) in research on individual learning in organizations in order to pay even closer attention to individual narratives. This attention 
serves not just to explore and cater to the narcissistic needs of learners (Perriton, 2007) but, importantly, to render transparent and amplify learning as an encounter with fundamental lack. In so doing learning may come into view not just as an objective phenomenon that may fail to deliver results (Hardless et al., 2005) or to question existing power structures (Contu et al., 2003) but also as a failure of the imaginary and an empowering struggle with identity and desire.

Future research may investigate this further by examining particular narratives of learners and how they construct the self in imaginary fashion. Similar to a recent study conducted by Nancy Harding (2007), interviews with learners or the feedback they provide in other forms could be examined for how the learning identities are constructed in particular moments and through particular expressions and how these imaginary constructions fail in particular moments that are held up for reflection between interviewer and interviewee (see Harding, 2007). As such, future research could focus more intently on how failure points of imaginary constructions can be rendered transparent and amplified so that the resulting potentially emancipatory space may be widened (Reynolds, 1998) as a lived experience (Cunliffe, 2002) of lack.

The latter point also highlights the second contribution this study hopes to make. Learning has been both criticized as being highly constrained by organizational power structures and ideologies (Contu et al., 2003; Coopey, 1998; Hollingshead and Michailova, 2001; Huzzard, 2000) as well as praised for its emancipatory potential (Reynolds, 1998) as a means to challenge organizational power and control through reflection and changing conversations (Bryans and Mavin, 2003; Cunliffe, 2002; Ferdinand, 2004; Fletcher and Watson, 2007; Garrick and Clegg, 2001; Hughes, 2000; 
Huzzard, 2000; Lorbiecki, 2001). The present study extends this research by offering a new perspective on learning, namely that, from a Lacanian perspective, learning is always already both conformity as well as subversion.

To the extent that we construct imaginary selves through learning discourse, we are always already controlled by an imaginary order in which we subjugate the self and its desires as objects of the ego. However, as the imaginary invariably fails, we also always have the opportunity to experience the self as emancipated and creative subject of the unconscious, which is, at least momentarily, free of any control. Consequently, the present study suggests that learning is always already an emancipatory space (Reynolds, 1998) in which the performative is appropriated by us to experience the self as subject of the unconscious. Learning, especially when we are most certain of who we are and what we desire as the learner, is always already subverted by the reiteration of lack; and learning discourse, no matter how much it aims at being performative (Contu et al., 2003), is always also appropriated by the self.

Therefore it is precisely because learning is inevitably a linguistic and identitybased phenomenon (Gherardi, Nicolini and Odella, 1998) that it is also always emancipatory. It is so not because we consciously narrate it as a critical and democratic practice (Cunliffe, 2002), which would only be another imaginary construction, but because we appropriate it for experiencing lack and liberation. The primitive freedom to learn beyond the reproduction of dominant ideologies (Coopey, 1998) may not only be enhanced by safer learning spaces (Coopey, 1998) where we can engage in public reflection (Raelin, 2001). 
Rather it may exist also in the exploration of discursive and conversational spaces (Baker et al., 2005; Fulop and Rifkin, 1997) where we listen more intently (Jacobs and Coghan, 2005) to the many failure points that mark our common, conscious narratives of learning with ambiguities, contradictions and other creative disruptions by the unconscious. So, for example, as Vincent wonders whether he is really doing anything different as a result of his learning (Rigano and Edwards, 1998: 442), participants in a conversation could discuss what each of them expects from learning, what "different" may mean for Vincent and for each of them and how, in the past, they may have learned but still not been certain or satisfied. This could be a learning conversation where lack is amplified but also where we confirm that we must keep wishing to articulate and fill this lack nonetheless.

Recent research has found that learning is often marked by the experience of lack (Jacobs and Coghan, 2005) and empty spaces (Cortese, 2005). The present study highlights the importance of such findings as a critical way forward to explore learning as and encounter with the lack of self, work and organization (Arnaud and Vanheule, 2007). This may also allow us to investigate learning discourse from a radically new point of view, namely that the experience of lack is not only inevitable but valuable in learning. As one participant in an action learning program describes:

Certainly I believe there are high expectations of me, and I have high expectations of myself to deliver it, but I have never actually tested that out and said: 'What happens if I don't? What happens if I demonstrate that I can't always be in control, that I can't always demonstrate that I am always right?' (Vince, 2002: $67)$.

It is precisely our failure to deliver to our expectations and to encounter that we not only cannot deliver on them, cannot be in control, cannot be right and, importantly, do not 
wish to be so in the first place, that makes learning discourse so valuable to us as subjects of the unconscious. In other words, learning discourse serves as an important resource (Hardy, 2001) to experience and possibly widen the space in organizations where we are free to roam as subjects of the unconscious (Arnaud and Vanheule, 2007) and can encounter the lack that marks and empowers us.

From a Lacanian perspective, the "positive value" of learning is not, as one of the reviewers put it, "to deny [the] possibility [that] an individual is personally motivated to learn and change", but rather to highlight the power of this desire in spite of its failure to be fulfilled. As we examine more closely how learning discourse invariably becomes an opportunity to articulate lack, we may shift our attention from looking at the many failures of individual learning in organizations as mistakes we can and should correct to celebrating them as powerful reminders that for all its fantastic qualities we can never stop wishing to learn.

\section{References}

Alvesson, M., and Skoldberg, K. 2000. Reflexive Methodology. London: Sage.

Arnaud, G. 2002. The organization and the symbolic: Organizational dynamics viewed from a Lacanian perspective. Human Relations, 55(6), 691-716.

Arnaud, G. 2003a. A coach or a couch? A Lacanian perspective on executive coaching and consulting. Human Relations, 56(3): 1131-1143.

Arnaud, G. 2003b. Money as signifier: A Lacanian insight into the monetary order. Free Associations, 10(53): 25-43.

Arnaud, G. and Vanheule, S. 2007. The division of the subject and the organization: A Lacanian approach to subjectivity at work. Journal of Organizational Change Management, 20(3): 359-369.

Baker, A.C., Jensen, P.J. and Kolb, D.A. 2005. Conversation as experiential learning. Management Learning, 36(4): 411-427. 
Boje, D.M., Luhman, J.T. and Baack, D.E. 1999. Hegemonic stories and encounters between storytelling organizations. Journal of Management Inquiry, (8)4: 340-360.

Bryans, P. and Mavin, S. 2003. Women learning to become managers: Learning to fit in or to play a different game? Management Learning, 34(1): 11-134.

Contu, A., Grey, C. and Oertenblad, A. 2003. Against learning. Human Relations, 56(8): 931-952.

Coopey, J. 1998. Learning to trust and trusting to learn: A role for radial theatre. Management Learning, 29(3): 365-382.

Cope, J. 2003. Entrepreneurial learning and critical reflection: Discontinuous events as triggers for 'higher-level' learning. Management Learning, 34(4): 429-450.

Cortese, C.G. 2005. Learning through teaching. Management Learning, 36(1): 87-115.

Cunliffe, A.L. 2002. Reflexive dialogical practice in management learning. Management Learning, 33(1): 35-61.

Driver, M. 2005. From empty speech to full speech? Reconceptualizing spirituality in organizations based on a psychoanalytically-grounded understanding of the self. Human Relations, 58(9): 1091-1110.

Driver, M. 2006. Beyond the stalemate of economics versus ethics: Corporate social responsibility and the discourse of the organizational self. Journal of Business Ethics, 66: 337-356.

Driver, M. 2008. New and Useless: A Psychoanalytic Perspective on Organizational Creativity. Journal of Management Inquiry.

Driver, M. 2009a. "Struggling with Lack: A Lacanian Perspective on Organizational Identity", Organization Studies 30(1): 55-72.

Driver, M. 2009b. Encountering the Arugula Leaf: The Failure of the Imaginary and Its Implications for Research on Identity in Organizations. Organization, 16(4): 487-504.

Fenwick, T. 2005. Ethical dilemmas of critical management education: Within classrooms and beyond. Management Learning, 36(1): 31-48.

Fletcher, D.E. and Watson, T.J. 2007. Entrepreneurship, management, learning and negotiated narratives: 'Making it otherwise for us - otherwise for them'. Management Learning, 38(1): 9-26. 
Fotaki, M. 2009. Maintaining the illusion of a free healthcare in post-socialism: A Lacanian analysis of transition from planned to market economy. Journal of Organizational Change Management, 22(2): 141-158.

Fulop, L. and Rifkin, W.D. 1997. Representing fear in learning in organizations. Management Learning, 28(1): 45-63.

Garrick, J. and Clegg, S. 2001. Stressed-out knowledge workers in performative times: A postmodern take on project-based learning. Management Learning, 32(1): 119-134.

Gherardi, S., Nicolini, D. and Odella, F. 1998. Toward a social understanding of how people learn in organizations: The notion of situated curriculum. Management Learning, 29(3): 273-297.

Harding, N. 2007. On Lacan and the becoming-ness of organizations/selves. Organization Studies, 28(11): 1761-1773.

Hardless, C., Nilsson, M. and Nulden, U. 2005. 'Copernicus': Experiencing a failing project for reflection and learning. Management Learning, 36(2): 181-217.

Hardy, C. 2001. Researching organizational discourse. International Journal of Management \& Organization, 31(3), 25-48.

Hemetsberger, A. and Reinhardt, C. 2006. Learning and knowledge-building in opensource communities: A social-experiential approach. Management Learning, (37(2): 187214.

Hollingshead, G. and Michailova, S. 2001. Blockbusters or bridge-builders? The role of Western trainers in developing entrepreneurialism in Eastern Europe. Management Learning, 32(4): 419-436.

Hughes, C. 2000. Painting new (feminist) pictures of human resource development (and) identifying research issues for political change. Management Learning, 31(1): 51-65.

Huzzard, T. 2000. From partnership to resistance: Unions and organizational learning at Ericsson Infocom. Management Learning, 31(3): 353-373.

Jacobs, C. and Coghlan, D. 2005. Sound from silence: On listening in organizational learning. Human Relations, 58(1): 115-138.

Jones, C., and Spicer, A. 2005. The sublime object of entrepreneurship. Organization, 12: 223-246.

Korthagen, F.A.J. 2005. The organization in balance: Reflection and intuition as complementary processes. Management Learning, 36(3) 371-387. 
Lacan, J. 1977a. Ecrits. New York: Norton.

Lacan, J. 1977b. The four fundamental concepts of psychoanalysis. London: Hoghart Press.

Lacan, J. 1988a. The seminar of Jacques Lacan, Book I: Freud's papers on technique 1953-1954. New York: Norton.

Lacan, J. 1988b. The seminar of Jacques Lacan, Book II: The ego in Freud's theory and in the technique of psychoanalysis 1954-1955. New York: Norton.

Lacan, J. 2001. Autres Ecrits. Paris: Editions Du Seuil.

Lorbiecki, A. 2001. Changing views on diversity management: The rise of the learning perspective and the need to recognize social and political contradictions. Management Learning, 32(3): 345-361.

Parker, M. 2004. Becoming manager or, the werewolf looks anxiously in the mirror, checking for unusual facial hair. Management Learning, 35(1): 45-59.

Perriton, L. 2007. The personal becomes polemical? The problematic second generation of facilitative practice. Management Learning, 38(2): 155-171.

Raelin, J.A. 2001. Public reflection as the basis of learning. Management Learning, 32(1): 11-30.

Reynolds, M. 1998. Reflection and critical reflection in management learning. Management Learning, 29(2): 183-200.

Rigano, D. and Edwards, J. 1998. Incorporating reflection into work practice: A case study. Management Learning, 29(1): 431-416.

Roberts, J. 2005. The power of the 'imaginary' in disciplinary processes. Organization, 12(5): 621-645.

Sveningsson, S. and Alvesson, M. 2003. Managing managerial identities: Organizational fragmentation, discourse and identity struggle. Human Relations, 56(10): 1163-1180.

Thursfield, D. 2008. Managers' learning in a UK local authority: The political context of an in-house MBA. Management Learning, 39(3): 295-309.

Van der Sluis, L.E.C. and Poell, R.F. 2002. Learning opportunities and learning behaviors: A study among MBAs in their early career. Management Learning, 33(3): 291-311. 
Vanheule, S., Lievrouw, A., and Verhaeghe, P. 2003. Burnout and intersubjectivity: A psychoanalytical study from a Lacanian perspective. Human Relations, 56(3), 321-338.

Vince, R. 2002. Organizing reflection. Management Learning, 33(1): 63-78.

Vince, R. and Saleem, T. 2004. The impact of caution and blame on organizational learning. Management Learning, 35(2): 133-154. 